\title{
Os Usos e Coberturas da Terra Afetados pelo Rompimento da Barragem de Fundão, Mariana - MG
}

\section{Land Use and Land Cover Changes Caused by Fundão dam Disruption, Mariana - MG}

\author{
Marcos Luciano Rios \\ Universidade Federal de São João del-Rei (UFSJ), Brasil \\ marcoslrios@ufsj.edu.br \\ Francielle da Silva Cardozo \\ Programa de Pós-Graduação em Geografia (PPGeog) \\ Universidade Federal de São João del-Rei (UFSJ), Brasil \\ franciellecardozo@ufsj.edu.br \\ Gabriel Pereira \\ Departamento de Geociências (DEGEO) \\ Universidade Federal de São João del-Rei (UFSJ), Brasil \\ pereira@ufsj.edu.br \\ Leonardo Cristian Rocha \\ Departamento de Geociências (DEGEO) \\ Universidade Federal de São João del-Rei (UFSJ), Brasil \\ rochageo@ufsj.edu.br
}

\begin{abstract}
Resumo
O Brasil viveu em novembro de 2015 o maior desastre ambiental de sua história, o rompimento da barragem de rejeitos de Fundão pertencente à empresa Samarco. Neste contexto, este trabalho busca mapear e quantificar os usos e coberturas da terra e sua relação com os aspectos socioeconômicos oriundos do rompimento da barragem de Fundão em Mariana - Minas Gerais. A área de estudo pretendida será os subdistritos de Bento Rodrigues e Paracatu de Baixo, pertencentes à Mariana que foram devastados pela lama de rejeitos em novembro de 2015. Nos dois distritos cerca 300 famílias perderam, além dos bens materiais, sua identidade, as histórias de vida e de convívio social. As histórias, o patrimônio arquitetônico e cultural foi-se com a lama de rejeitos. Num primeiro momento, fundamentado nos trabalhos e relatórios dos órgãos oficiais, nota-se que os efeitos do rompimento da barragem sobre o ambiente ainda não foram consolidados, pois se trata de fato recente, necessita da conjugação de esforços, do trabalho multidisciplinar de órgãos da sociedade civil e de governo para uma melhor definição desses efeitos. Os mapas de usos retratam a devastação oriunda do rompimento. Os resultados do mapeamento indicam que aproximadamente 496 hectares de floresta densa foram afetados pela lama na área delimitada no estudo. Além disso, 116 ha e 52 ha de vegetação herbáceoarbustiva e solo exposto, respectivamente, foram suprimidos pelo rompimento. Em relação às classes de uso e cobertura do solo referentes às áreas urbanas, pastagem, reflorestamento e agricultura, foram afetados 19 ha, 18 ha, 7 ha e 1 ha, respectivamente.
\end{abstract}

Palavras-chave: Bento Rodrigues, Paracatu de Baixo, Samarco, Barragem de Fundão. 


\begin{abstract}
In November 2015, Brazil experienced the larger environmental disaster in its history, the Fundão dam rupture from Samarco company. In this context, this work aims to map and quantify land use. Land cover changes (LULCC) and its relationship with the socioeconomic aspects derived from the rupture occurred in Mariana, Minas Gerais state, more specifically in Bento Rodrigues' sub-districts Paracatu de Baixo of Mariana, which were devastated by the mud in November 2015. In the study area, approximately 300 families lost material goods, identity, the stories of life and social life. The stories, the architectural and cultural heritage was gone with the mud of this disaster. Initially, based on the work and reports of official institutions, it is noted that the effects of the rupture of the dam on the environment have not yet been consolidated, since it is a recent fact, it requires the combination of efforts, the multidisciplinary work of the civil society institutions and government to define these effects better. The land use and landcover (LULC) maps presented the devastation resulting from this disruption. The mapping results indicate that approximately 496 hectares of dense forest were affected by the mud in the area defined in the study. Also, 116 ha and 52 ha of herbaceous-shrub vegetation and bare soil, respectively, were suppressed by the breach. Concerning the LULC referring to urban areas, reforestation, pasture and agriculture, 19 ha, 18 ha, 7 ha and 1 ha were affected, respectively.
\end{abstract}

Keywords: Bento Rodrigues, Paracatu de Baixo, Samarco, Fundão Dam.

\title{
1. INTRODUÇÃO
}

As relações de mercado ao longo do tempo no contexto da articulação global sofrem constantes mudanças. Segundo ALTVATER (1985), liberalismo e capitalismo são concepções e realidades que se integram e se confundem num mesmo processo de construção histórica. Têm a mesma gênese e expressam realidades que se interpenetram. Segundo Campos (2000) o desenvolvimento econômico global tem exercido uma pressão sobre os sistemas naturais, com efeitos diversos sobre a qualidade do ambiente, levando-o à exaustão ou degradação.

As alterações físicas e biológicas ao longo do tempo modificam a paisagem e comprometem os ecossistemas. Segundo Fernandez (2004), as alterações ambientais ocorrem por inúmeras causas, muitas denominadas naturais e outras oriundas de intervenções antropológicas, consideradas nãonaturais. Os desafios em relação aos problemas ambientais ultrapassam os limites sistêmicos e as fronteiras das nações, buscando o redirecionamento das perspectivas econômicas. Esta preocupação tem figurado no bojo do relacionamento, integração e cooperação entre países, sendo que muitos projetos e a carência de administração de recursos têm trazido implicações concretas diante da extração de recursos naturais, dos limites da natureza e das rápidas mudanças que esta vem apresentando na história recente (AGENDA 21, 1992).

As relações de produção na conjuntura econômica globalizada levam em consideração vários fatores inibidores e estimulantes no processo produtivo, buscando a maximização dos recursos e um maior grau de eficiência. Dentre esses fatores, destaca-se a proteção do meio ambiente, que ganhou importância na década de 1970, quando nos países desenvolvidos aflorou a percepção de que o bem- 
estar social, fruto do desenvolvimento econômico, estava diretamente relacionado a impactos não desejados sobre os vários ecossistemas.

Segundo Campos (2000), as alternativas de exploração dos recursos naturais advindas da revolução industrial alimentaram a perspectiva do lucro imediato, negligenciando a possibilidade de esgotar o estoque de "capital natural”. A integração financeira e comercial, após a segunda guerra mundial, acelerou o dinamismo econômico das nações, ampliando as expectativas de superação do atraso econômico dos países do "terceiro mundo", nos moldes das teorias desenvolvimentistas das sociedades ocidentais. Neste contexto, o crescimento se tornou condição necessária e suficiente para o desenvolvimento econômico, visto como uma decorrência natural do avanço tecnológico, capaz de garantir o bem-estar social.

Mediar a relação entre desenvolvimento econômico e a preservação dos recursos naturais não é tarefa fácil no cenário globalizado e de intensas modificações. As economias com as maiores reservas de recursos, são as que mais precisam incrementar seus processos de desenvolvimento implicando a utilização de recursos naturais. O Brasil não fica fora desse cenário, devido principalmente às suas reservas de recursos naturais, diversidade de fauna e flora e recursos minerais. Assim, a atividade de mineração, importante para a promoção do crescimento econômico e do bemestar social, tem sido responsável pela modificação de grandes extensões da paisagem do território nacional. Em geral, essa atividade envolve a movimentação de grande quantidade de terra, deixando o solo exposto e desestabilizado, sujeito à erosão acelerada, o que provoca várias alterações ambientais nos ecossistemas (ARRUDA, 1985; CAMPOS, 2000).

A mineração compreende um conjunto de atividades destinadas a pesquisar, descobrir, mensurar, extrair, tratar ou beneficiar e transformar recursos minerais de forma a torná-los benefícios econômicos e sociais (REIS et al., 2016). Tal atividade tem forte impacto na economia brasileira, representando de 3\% a 5\% do PIB (Produto Interno Bruto) e representa 7,5\% do produto interno bruto do estado de Minas Gerais (BRASIL, 2019). Segundo levantamento realizado pela Fundação Estadual do Meio Ambiente (FEAM), Minas Gerais tem um total de 450 barragens de rejeitos de minério. Tal fato torna o estado vulnerável a rompimentos como o ocorrido em Mariana em novembro de 2015, onde a barragem de Fundão se rompeu, provocando mortes, desabastecimento de água, interrupção da atividade pesqueira e danos incalculáveis a biodiversidade da região até a foz do Rio Doce no oceano Atlântico.

Dentre os fatores causadores dos rompimentos de barragens destacam-se os fenômenos naturais e o planejamento estrutural inadequado. Esses fatores classificam-se em desastre misto (quando eventos naturais causam o rompimento) e em desastre tecnológico, que se caracteriza pela ausência de força externa. O rompimento da barragem do Fundão foi classificado pelo Governo Federal como desastre tecnológico (BRASIL, 2015). 
A Instrução Normativa $n^{\circ} 01$, de 24 de agosto de 2012, estabelece em seu Art. $7^{\circ}, \S 1^{\text {o: }}$ "Quanto à origem ou causa primária do agente causador, os desastres são classificados em: I Naturais e II - Tecnológicos. $§ 2^{\circ}$ São desastres naturais aqueles causados por processos ou fenômenos naturais que podem implicar em perdas humanas ou outros impactos à saúde, danos ao meio ambiente, à propriedade, interrupção dos serviços e distúrbios sociais e econômicos. $\S 3^{\circ}$ São desastres tecnológicos aqueles originados de condições tecnológicas ou industriais, incluindo acidentes, procedimentos perigosos, falhas na infraestrutura ou atividades humanas específicas, que podem implicar em perdas humanas ou outros impactos à saúde, danos ao meio ambiente, à propriedade, interrupção dos serviços e distúrbios sociais e econômicos (BRASIL, 2018).

De acordo com o estudo realizado pela Browker Associates, que fez análises comparativas entre outras ocorrências similares, apenas cinco acidentes com barragens de rejeitos no mundo excederam 10 milhões de $\mathrm{m}^{3}$ de lançamentos (OLIVEIRA, 2018). Ainda segundo este mesmo autor:

\footnotetext{
Embora os números exatos permaneçam um pouco distorcidos, a diferença de magnitude em relação a catástrofes passadas torna inequivocadamente claro que o caso da Samarco é o pior registrado na história sobre essas três medidas de gravidade", pontua Lindsay NewlandBowker, coordenadora da Bowker Associates. O estudo registra, de 1915 a 2015, um total de 129 eventos com barragens - de 269 conhecidos - e projeta em média, um acidente grave por ano no período de uma década. Todas as catástrofes na mineração são ocasionadas por erro humano e falhas ao não se seguir as melhores práticas estabelecidas, $o$ melhor conhecimento, a melhor ciência.
}

Com frequência, a ação do homem como agente geológico-geomorfológico é mais intensa que processos equivalentes que acontecem de forma natural (PELOGGIA; OLIVEIRA, 2005), portanto, fenônemos que demorariam um período de tempo muito maior para se manifestarem na escala de tempo da natureza, ocorrem de forma muito mais rápida pela ação humana (PEREZ FILHO; QUARESMA, 2011). Neste contexto, este trabalho tem como objetivo principal mapear os usos e ocupações da terra quantificando minimamente a degradação provocada pelo rompimento da barragem de fundão nos distritos de Bento Rodrigues e de Paracatu de Baixo, pertencentes à Mariana $-\mathrm{MG}$.

\section{2. ÁREA DE ESTUDO}

O distrito de Bento Rodrigues é subdistrito de Santa Rita Durão (distrito de Mariana, Figura 1), foi fundado em 1698 pelo bandeirante Bento Godoy Rodrigues e tornou-se um importante centro de mineração nos séculos XVII e XVIII. No povoado viviam cerca de 600 habitantes e a atividade econômica baseava-se no comércio varejista, com a produção de hortifrutigranjeiros, alimentos e bebidas e contava também com uma pequena fábrica de geleia de pimenta biquinho e de uma empresa de consultoria empresarial especializada (GOVERNO DO ESTADO DE MINAS GERAIS, 2015). 
BARRAGEM DO FUNDÃO

Mariana - MG

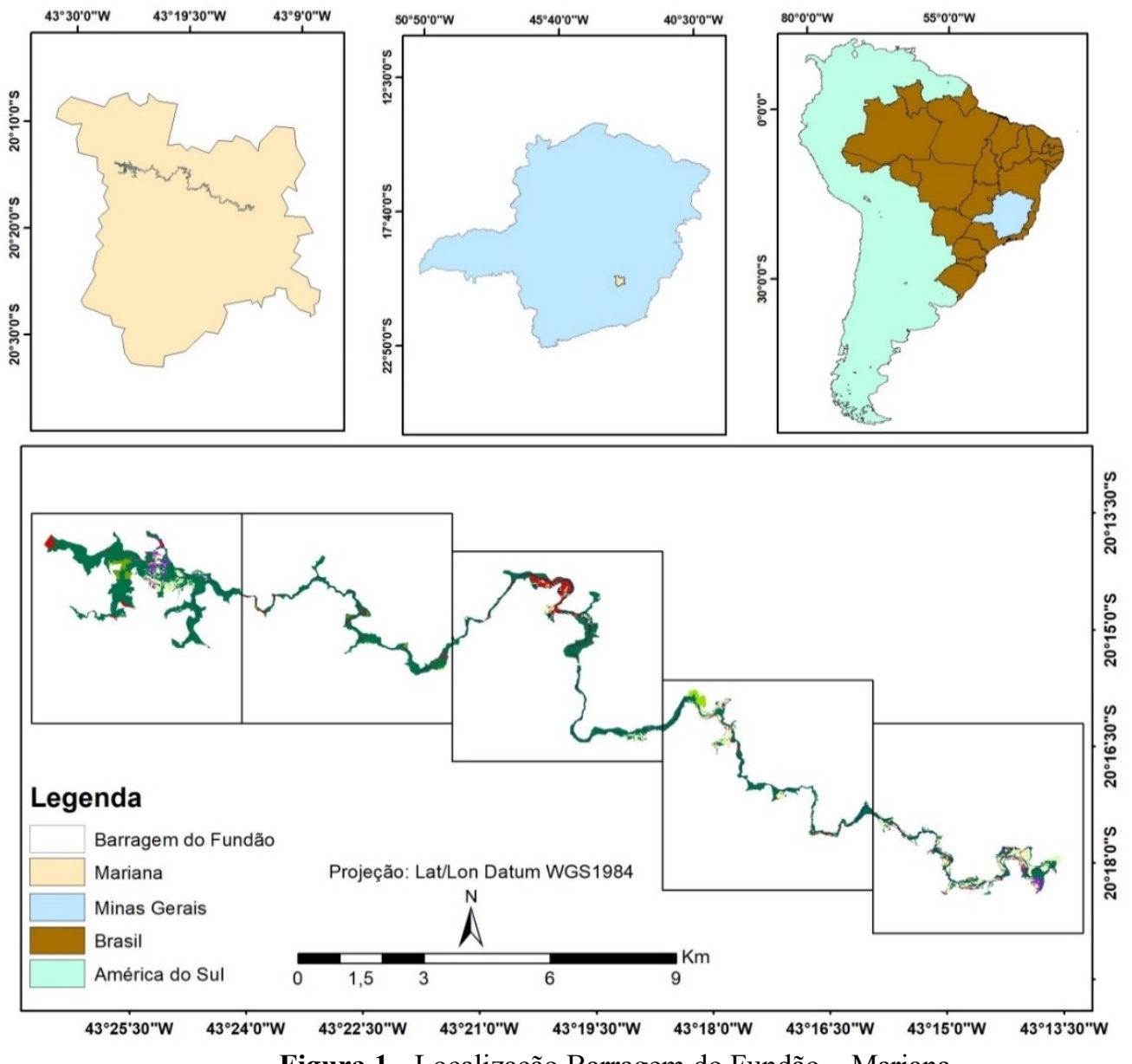

Figura 1 - Localização Barragem do Fundão - Mariana.

Bento Rodrigues, embora vilarejo era distrito que possuía uma história majestosa e digna de orgulho entre seus concidadãos. Com 317 anos de existência, abrigava igrejas centenárias com obras sacras importantes e monumentos de notória relevância cultural, além de fazer parte da rota da Estrada Real no século XVII. Além das perdas de vidas humanas, cujos valores são incalculáveis, em apenas onze minutos de avalanche todo patrimônio histórico e cultural, construído ao longo de séculos, fora dizimado pelo mar de rejeitos (GOVERNO DO ESTADO DE MINAS GERAIS, 2015).

Além disso, o povoado, por ter sido um importante centro de mineração no século XVIII, integrava o Caminho dos Diamantes da Estrada Real, que interligava os distritos de Santa Rita Durão e Camargos, realizando a rota de Minas Gerais ao Rio de Janeiro (MPMG, 2016).

Segundo consta do Dossiê de Tombamento de Bento Rodrigues, as falas de moradores de Bento reforçam a função antiga de entreposto de apoio aos viajantes, agora ligada à exploração turística da estrada real, que se praticava em Bento, antes de ser devastada pela lama de rejeitos de Fundão. Da mesma forma, as atividades agrárias foram muito mais citadas como as atividades econômicas centrais da população do que ligadas à mineração (CASTRIOTA et al., 2019). 
Segundo apontado na Denúncia do Ministério Público Federal (MPMG, 2016), “em Bento Rodrigues a inundação causou o desabamento de vários imóveis residenciais, comerciais, igrejas, pontes e prédios públicos, deixando mais de 300 (trezentas) famílias desabrigadas, além de vítimas fatais. Na corrida pela vida, a grande maioria dos moradores de Bento Rodrigues não teve tempo de salvar quaisquer pertences, sendo obrigados a fugirem para terrenos mais altos na região, onde não pudessem ser arrastados/soterrados pela lama”.

Ressalta-se que a localidade atraía inúmeros visitantes para suas festas, dentre as quais destacam-se as manifestações culturais e religiosas como a Festa de São Bento, realizada no último final de semana do mês de julho; a Festa de Nossa Senhora das Mercês, realizada no mês de setembro; a Festa de São Sebastião, de São José, de Nossa Senhora das Dores, Maria Concebida, do Sagrado Coração de Jesus, de São Benedito e do Menino de Jesus (CASTRIOTA et al., 2019, p.88).

O distrito de Paracatu de Baixo, conforme figura 1 é um subdistrito de Monsenhor Horta e está localizado a $34 \mathrm{~km}$ de Mariana e a $9 \mathrm{~km}$ de Monsenhor Horta. O espaço urbano do distrito é articulado pela presença do Rio Gualaxo do Norte, da estrada que corta o subdistrito, da igreja de Santo Antônio, do campo de futebol e da escola construída para ensino infantil e fundamental (classes multisseriadas). No que diz respeito ao impacto causado nas habitações, aduziu que "das 251 edificações mapeadas em Bento Rodrigues, 207 apresentaram sobreposição com o polígono da área atingida, ou seja, 82\% das edificações foram atingidas” (BRASIL, 2019).

Os impactos causados ao meio ambiente por essa atividade são enormes e de difícil valoração, e as políticas de prevenção e de licenciamento ambiental muitas vezes não são acompanhadas de fiscalização, seja por falta de aparato para a realização dos trabalhos ou por extrema falta de organização e despreparo dos órgãos responsáveis pelas autorizações. De acordo com Bitar (1997) a mineração é responsável por promover uma diversidade de efeitos não desejados, os impactos de grande relevância seriam: alterações ambientais, conflitos de uso do solo, depreciação de imóveis circunvizinhos, geração de áreas degradadas e transtornos ao tráfego urbano. Estes provocam conflitos com a comunidade, devido à falta de interesse do empreendimento em atender as necessidades da população.

\section{MATERIAS E MÉTODOS}

\subsection{Materiais utilizados}

Neste trabalho as imagens do Google Earth foram utilizadas para o mapeamento das áreas atingidas pelo rompimento da barragem de Fundão, pertencente ao complexo minerário de Germano, no município de Mariana/MG a partir da plataforma Google Earth. O Google Earth é um software gratuito que combina um mosaico imagens de satélite obtidas de fontes diversas com as características 
do terreno para fornecer uma renderização digital em 3D da superfície da Terra em uma interface considerada de fácil manipulação para o usuário final, podendo ser utilizado para a confecção de mapas bidimensionais, simulador de paisagens, identificação de lugares, construções, paisagens, entre outros (GOOGLE, 2020).

\subsection{Procedimentos Metodológicos}

A partir da plataforma online do Google Earth, delimitou-se a área de influência da lama a partir de uma imagem pós-evento disponível no programa. Assim, obteve-se a área de influência visivelmente afetada pela lama, traçou-se uma linha e vetorizou-se toda sua influência até o distrito de Paracatu de Baixo utilizando-se a ferramenta "Adicionar Polígono". A partir daí utilizou-se uma imagem pré-evento (disponível na própria plataforma), a partir da função “histórico", para determinar os usos e coberturas afetadas pela lama. A classificação do uso e cobertura da terra foram obtidos a partir de polígonos. Após o recorte espacial da área de estudo, as cenas foram inseridas no ArcGis 10.7, em formato Keyhole Markup Language (KML), que é uma linguagem baseada em XML e serve para expressar anotações geográficas e visualização de conteúdos existentes nessa linguagem como mapas em 2D e navegadores terrestre em 3D. Nesta etapa o mosaico dos planos vetoriais foi criado para que fosse representado então os usos do solo da área de estudo em questão, isto é, para selecionar os usos do solo da área de interesse com o objetivo de criar uma nova imagem que represente a área de estudo em questão.

A etapa seguinte foi realizada no Sistema de Processamento de Informações Georreferenciadas - SPRING versão 5.5.2, utilizou-se a imagem Sentinel, com resolução espacial de 10 m, para realizar o mosaico, criação de bancos de dados e composição da composição falsa-cor, tendo em vista a dar suporte para os mapas vetoriais extraídos a partir da plataforma online do Google Earth (Figura 2). As etapas podem ser observadas no fluxograma abaixo:

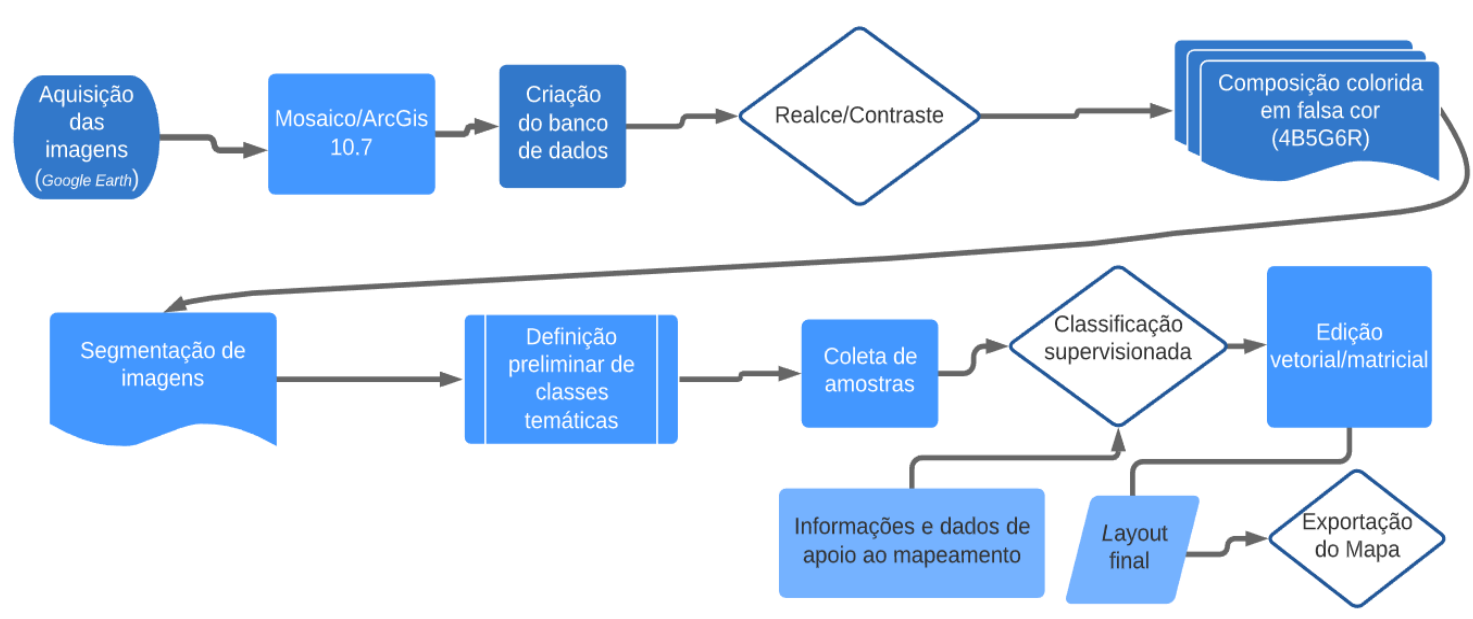

Figura 2 - Fluxograma das etapas do mapeamento. 


\section{RESULTADOS E DISCUSSÃO}

O município de Mariana é regido por duas unidades geomorfológicas principais, o Quadrilátero Ferrífero em sua porção mais oeste, culminando na Serra do Caraça, e os planaltos dissecados do Rio Doce na porção restante do território (CPRM, 1994). A unidade geomorfológica “Quadrilátero Ferrífero" é caracterizada por possuir altitudes médias em torno de 1.400 a 1.600 metros de altitude (CRPM, 1994), sendo seu ponto culminante localizado na Serra do Caraça $(2.064 \mathrm{~m})$.

As rochas metamórficas pré-cambrianas contêm as jazidas de ferro "sendo a Formação Cauê, de idade paleoproterozóica, a que se oferece maior interesse econômico, devidos aos seus importantes depósitos ferríferos de elevado teor e pureza" (GODOY, 2017, p.21). Além disso, o município de Mariana situa-se na Bacia do Rio Doce, banhada pelo Rio do Carmo, que possui dois afluentes: Gualaxo do Norte e Gualaxo do Sul. A altitude máxima chega a 1.772 m no Pico do Itacolomi. Neste contexto, no dia 05 de novembro de 2015, o rompimento da Barragem do Fundão devastou os distritos de Bento Rodrigues e Paracatu de Baixo, pertencentes à Mariana levando destruição para os distritos e para o ambiente, transformando a paisagem da região.

Após o rompimento da barragem em novembro de 2015, algumas ações emergenciais foram implementadas pela SAMARCO S.A e suas controladoras no sentido de minimizar os impactos socioeconômicos e ambientais oriundos do maior desastre minerário do mundo. Dentre essas ações destacam-se: I) Realocação dos moradores/afetados que perderam seus lares; II) Distribuição de água potável e mineral; III) Resgate de animais; IV) Atendimento psicossocial; e V) Restabelecimento de acessos danificados.

Um dos principais componentes das paisagens terrestre estão relacionadas as mudanças no uso e cobertura da terra (UCT), estas são responsáveis por realizar alterações diretas na composição do habitat, da biodiversidade e funcionamento do ecossistema. E seus impactos geram consequências que afetam diretamente alguns processos, como os de degradação do solo e da biodiversidade, modificando as condições ambientais (GARCÍA-MOZO et al., 2016). Para uma melhor visualização de cada classe, optou-se por dividir a área de estudo em cinco partes (Mapa A, Mapa B, Mapa C, Mapa D e Mapa E), conforme as figuras 3, 4, 5, 6 e 7, respectivamente. 

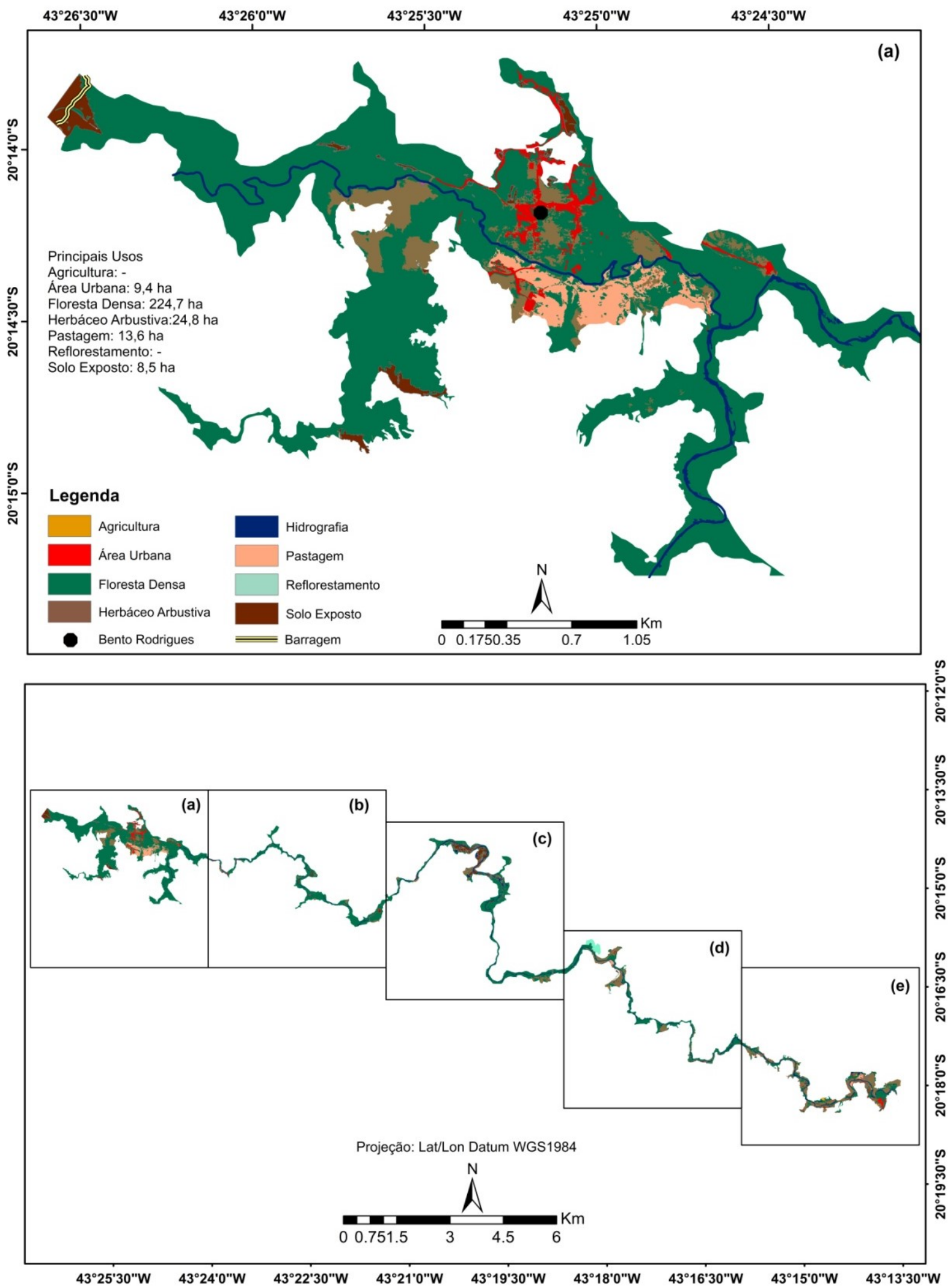

Figura 3 - Área afetada pelo rompimento da barragem do Fundão (A). 

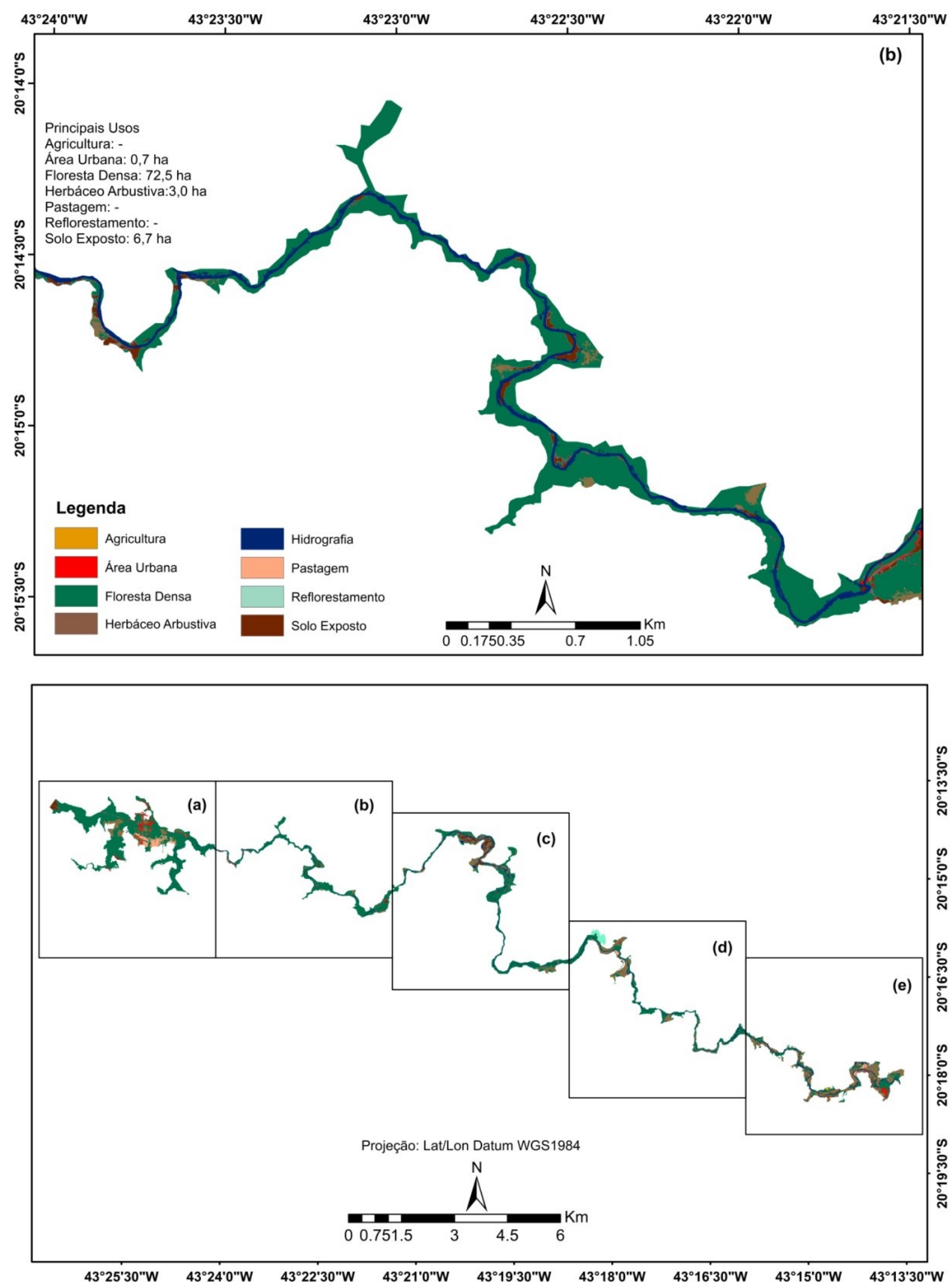

Figura 4 - Área afetada pelo rompimento da barragem do Fundão (B). 

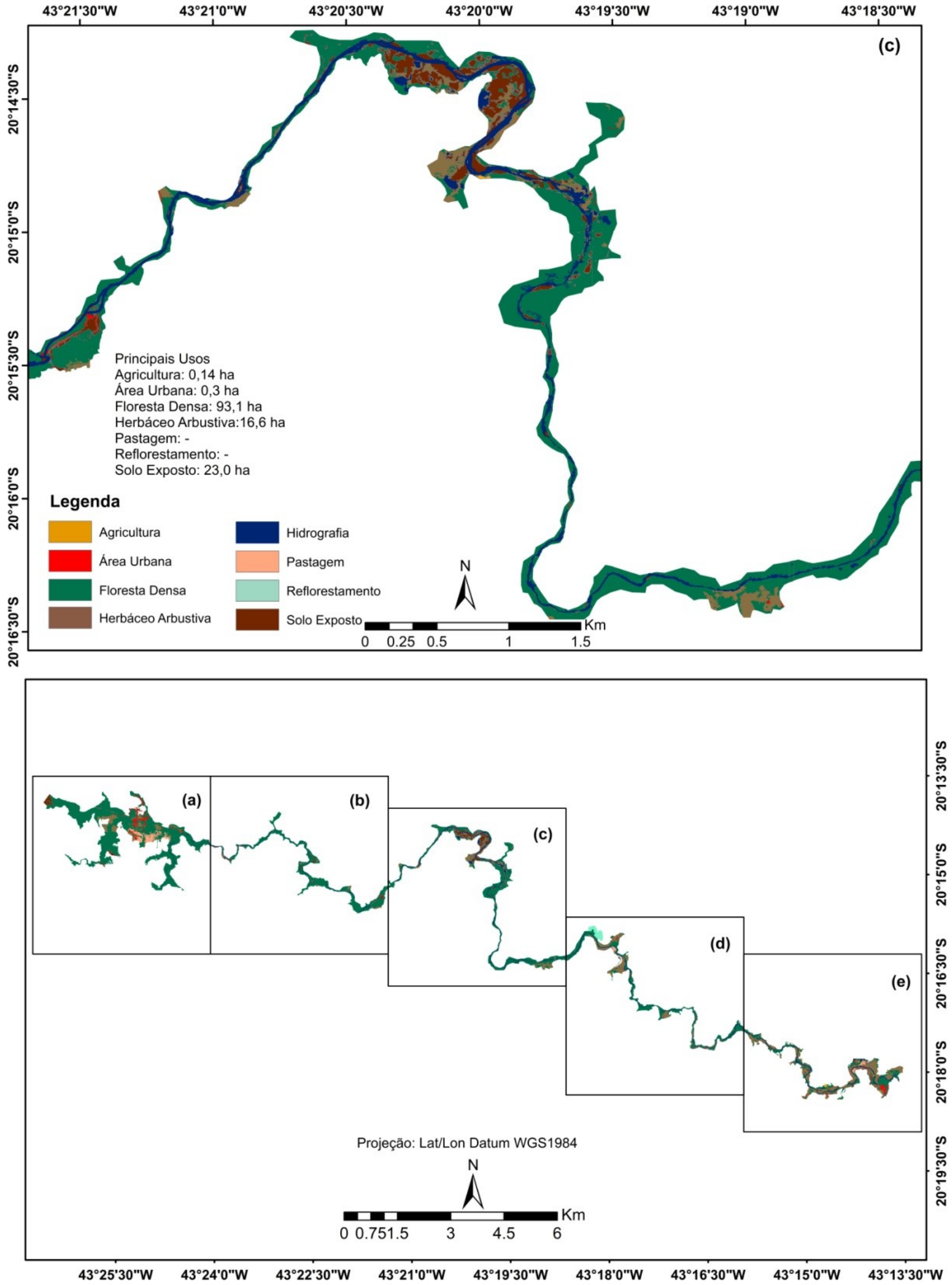

Figura 5 - Área afetada pelo rompimento da barragem do Fundão (C). 

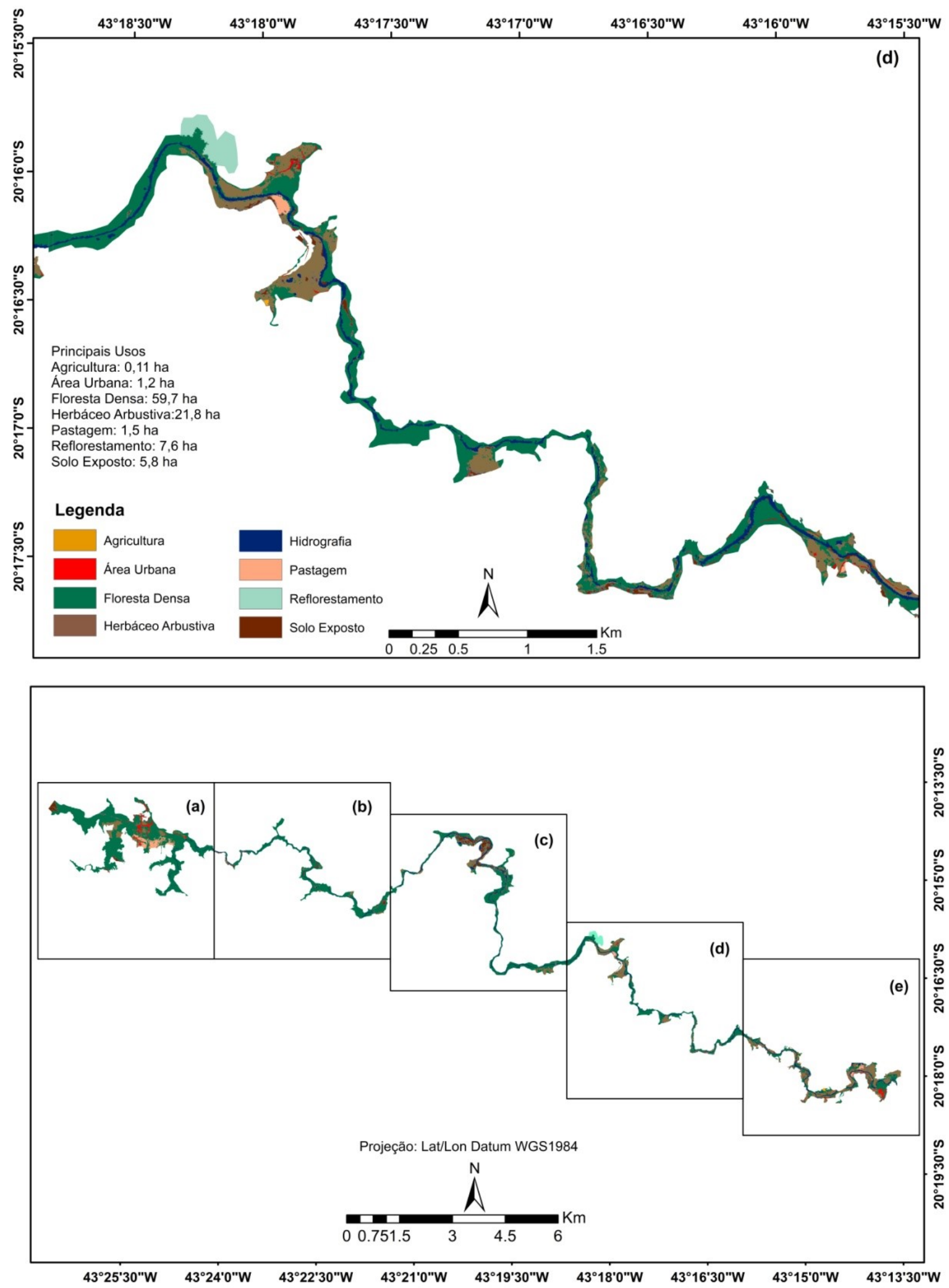

Figura 6 - Área afetada pelo rompimento da barragem do Fundão (D). 

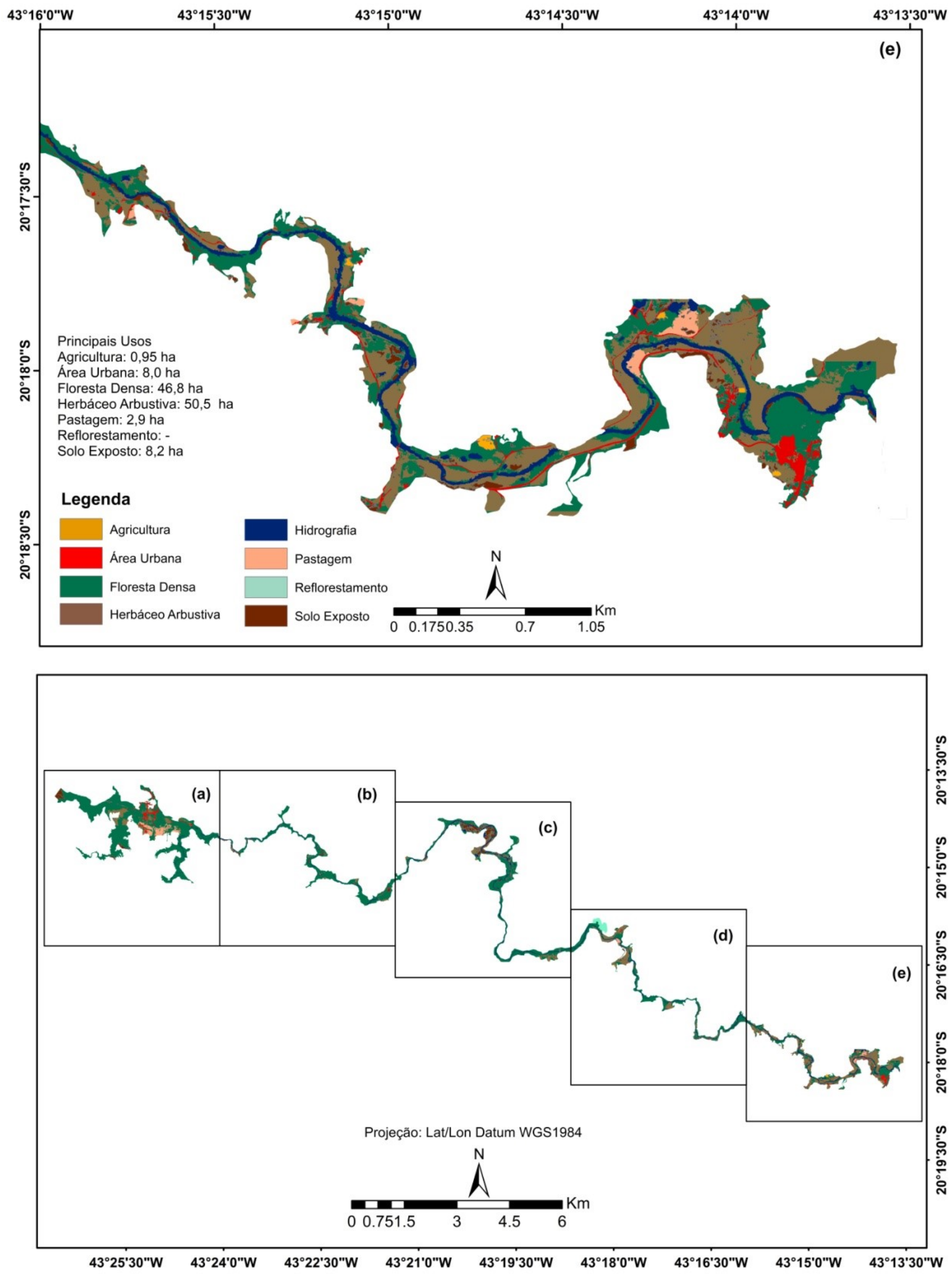

Figura 7 - Área afetada pelo rompimento da barragem do Fundão (E). 
O trabalho de mapeamento possibilitou a identificação dos principais usos da terra que foram afetados pelo rompimento da barragem de Fundão. Na área proposta para o estudo foram identificados os seguintes usos: agricultura, área urbana, floresta densa, herbáceo arbustivo, hidrografia, pastagem, reflorestamento e solo exposto (tabela 1).

Tabela 1: Usos área degradada.

\begin{tabular}{ccccccc}
\hline Classes (ha) & Mapa A & Mapa B & Mapa C & Mapa D & Mapa E & Total (ha) \\
\hline Floresta Densa & 224,70 & 72,50 & 93,10 & 59,70 & 46,80 & 496,80 \\
Área Urbana & 9,40 & 0,70 & 0,30 & 1,20 & 8,00 & 19,60 \\
Solo Exposto & 8,50 & 6,70 & 23,00 & 5,80 & 8,20 & 52,20 \\
Herbáceo Arbustiva & 24,80 & 3,00 & 16,60 & 21,80 & 50,50 & 116,70 \\
Pastagem & 13,60 & - & - & 1,50 & 2,90 & 18,00 \\
Agricultura & - & - & 0,14 & 0,11 & 0,95 & 1,20 \\
Reflorestamento & - & - & - & 7,60 & - & 7,60 \\
\hline
\end{tabular}

Segundo Motta (1998), primeiro devemos perceber que o valor econômico dos recursos ambientais é derivado de todos os seus atributos e, segundo, que estes atributos podem estar ou não associados a um uso. Ou seja, o consumo de um recurso ambiental se realiza via uso ou não-uso.

Os usos identificados neste trabalho são enquadrados segundo a taxonomia geral de Valor econômico do Recurso Ambiental em valores de uso direto e em valores de uso indireto. Na categoria de valor de uso direto, essas classes são fornecedoras de alimentos, nutrientes, turismo e etc. Em relação aos valores indiretos, essas classes estão associadas ao bem-estar humano, proteção dos corpos d'água, controle da erosão, provimento de oxigênio e recursos genéticos.

Uma vez que a área de estudo está inserida na região do quadrilátero ferrífero, o território de Mariana tem como principal vocação a atividade mineraria, sendo que os royalties recebidos pela municipalidade representam sua maior arrecadação, destacando-se a extração de minério de ferro, bauxita, manganês e ouro, exercida pela mineradora Samarco (SOUZA et al., 2005).

De acordo com o Censo IBGE de 2010, o povoado de Bento Rodrigues tinha 492 pessoas residentes, entre estes 241 homens e 251 mulheres. Havia 121 domicílios particulares permanentes, ou seja, domicílio construído exclusivamente com a finalidade de servir de moradia, 27 domicílios não-ocupados, 15 domicílios particulares permanentes não ocupados, de uso ocupacional, e nenhum domicílio improvisado.

$\mathrm{O}$ rompimento da barragem do Fundão transformou o cenário socioeconômico e socioambiental dos residentes/afetados em Bento Rodrigues e Paracatu de Baixo, os dois distritos pertencentes à Mariana que mais sofreram os impactos da lama de rejeitos. O rompimento da 
barragem do fundão dizimou o distrito de Bento Rodrigues, o patrimônio arquitetônico, a paisagem urbana, a paisagem rural e a identidade de seus moradores. Em poucos minutos, séculos de história e o cotidiano do pacato distrito, as relações de vizinhança foram totalmente destruídas.

Dentre os aspectos socioeconômicos destacamos os danos às propriedades rurais, o comprometimento da atividade agrícola, os danos a infraestruturas públicas e privadas, os danos às residências, comércio e outros. Segundo Poemas (2015):

O povoado rural de Paracatu de Baixo, não corresponde sozinho a um setor censitário, estando, porém, inserido em um dos três setores censitários do distrito de Monsenhor Horta que tinha um total populacional de 1.740 habitantes. $O$ setor censitário onde se encontra Paracatu de Baixo ( $\left.n^{\circ} 314000135000002\right)$ é o mais extenso em área e totalizava uma população de 421 habitantes, em 2010. Paracatu de Baixo, porém, aparenta ser o maior aglomerado populacional dentro deste setor censitário.

Um aspecto fundamental na recuperação de áreas degradadas pela mineração é o conhecimento do solo onde essa recuperação será realizada. Os procedimentos específicos na recuperação dessas áreas dependem essencialmente das propriedades físicas, químicas e mineralógicas do solo que deverá ter condições para o adequado desenvolvimento das plantas (FONTES, 1991).

\section{CONSIDERAÇÕES FINAIS}

O rompimento da Barragem de Fundão provocou profundas alterações no ambiente e nas relações das pessoas nas cidades afetadas. A análise fundamentada e imparcial do modo de gestão aplicados a mineração no Brasil apresenta falhas de fiscalização, concessão de licenças ambientais e de gestão de riscos. A dependência da mineração é visível e a falta de diversificação econômica dos municípios, sem a adoção de políticas consistentes de renda e desenvolvimento social faz com que as cidades não tenham alternativas no curto prazo de superarem eventos como o ocorrido na Barragem de Fundão.

As consequências dessa tragédia socioambiental e socioeconômica serão sentidas ainda por muito tempo, exemplo disso é que passados quatro anos do rompimento da barragem, várias ações ainda não contemplaram os moradores/afetados. As medidas emergenciais e as de curto prazo tem sido alvo de críticas por não contemplarem e não repararem em sua totalidade os danos causados.

As comunidades ainda não foram reconstruídas, atrasos nos licenciamentos e uma falta de ações propositivas só aumentam a angústia dos afetados.

Desta forma, este trabalho não esgota as possibilidades de levantamentos de mapeamento e quantificação, nosso desejo maior é que sirva de incentivo para que outros pesquisadores possam debruçar-se nesse momento em que essas tragédias tomam o cenário na busca de meios para recuperação das áreas afetadas e mitigar os danos causados às comunidades e a sociedade no geral. 
O tempo para o ressarcimento, reparos aos afetados não tem a mesma velocidade e potência do tempo de destruição. O desafio presente diante desse evento é não deixar cair no esquecimento e também não tornar desastres como esse em casos naturais, que repercutem em um primeiro momento, mas logo são esquecidos pela maioria, ficando apenas o desalento aos afetados.

\section{REFERÊNCIAS}

ALTVATER, E. O preço da riqueza. 1. ed. São Paulo: UNESP, 1995. 335p.

ARRUDA, A. T. Mineração e meio ambiente: aspectos técnicos e legais. In. DNPM/MME. Coletâneas de trabalhos técnicos sobre controle ambiental na mineração. Brasília: Biblioteca Nacional do Rio de Janeiro, 1985. p. 13-22.

BITAR, O. Y. Avaliação da recuperação de áreas degradadas por mineração na região metropolitana de São Paulo. 1997. 185 f. Tese (Doutorado) - Escola Politécnica da Universidade de São Paulo, Universidade de São Paulo, São Paulo, 1997.

BRASIL. MINISTÉRIO DO DESENVOLVIMENTO AGRÁRIO. Brasília: MDA. 2013. Disponível em: <www.mda.gov.br>. Acesso em: 20 ago. 2019.

BRASIL. Laudo Técnico Preliminar: Impactos ambientais decorrentes do desastre envolvendo o rompimento da barragem de Fundão, em Mariana, Minas Gerais. In. Instituto Brasileiro do Meio Ambiente e dos Recursos Naturais Renováveis - IBAMA. Minas Gerais, 2015. Disponível em: HTTP://www.ibama.gov.br/phocadownload/noticias_ambientais/laudo_tecnico_preliminar.pdf.

Acesso em: 07 mar. 2018.

CAMPOS, E. M. G. Avaliação econômica da erosão e conservação do solo agrícola: metodologia e aplicação no município de Lagoa Dourada. 2000. Tese (Doutorado) - Instituto Alberto Luiz Coimbra de Pós-Graduação e Pesquisa de Engenharia, Universidade Federal do Rio de Janeiro, Rio de Janeiro, 2000.

CASTRIOTA, L. B. Dossiê de tombamento Bento Rodrigues. Belo Horizonte, 2019. Disponível em: http://patrimoniocultural.blog.br/wp-content/uploads. Acesso em: 25 jan. 2021.

CONFERÊNCIA DAS NAÇÕES UNIDAS SOBRE O MEIO AMBIENTE E DESENVOLVIMENTO. Agenda 21. Centro de Informações das Nações Unidas, 1992.

COMPANHIA DE PESQUISA DE RECURSOS MINERAIS. Relatório da administração: exercício de 1993. Rio de Janeiro: CPRM, 1994.

FERNADEZ, F. A. S. O poema imperfeito: crônicas de Biologia, conservação da natureza, e seus heróis. 2. ed. Curitiba: UFPR, 2004. 264p.

FONTES, M. P. F. Estudo pedológico reduz impacto da mineração. Revista Cetesb de Tecnologia e Ambiente, v. 5, p. 58-61, 1991.

GARCÍA-MOZO, H.; OTEROS, J. A.; GALÁN, C. Impact of land cover changes and climate on the main airborne pollen types in Southern Spain. Science Of The Total Environment, v. 548, p. 221228, 2016. 
GODOY, L. Relatório Técnico de Geografia. In PÓLEN, Diagnóstico preliminar dos bens culturais identificados no território atingido em Mariana pelo rompimento da Barragem de Fundão. Lagoa Santa, 2017.

GOVERNO DO ESTADO DE MINAS GERAIS. Relatório: Avaliação dos efeitos e desdobramentos do rompimento da Barragem de Fundão em Mariana. Secretaria de Estado de Desenvolvimento Regional, Política Urbana e Gestão Metropolitana. Belo Horizonte 2016.

GOOGLE. Google Earth website. http://earth.google.com/. 2020.

MINISTÉRIO PÚBLICO DE MINAS GERAIS. Caso Samarco: Relatório de Atividades da Força Tarefa do MPMG. Belo Horizonte, MG, fevereiro 2016.

MOTTA, R. S. Manual para valoração econômica de recursos ambientais. Brasília: Ministério do Meio Ambiente, dos Recursos Hídricos e Amazônia Legal, 1998.

OLIVEIRA, N. Desastre em Mariana é o maior acidente mundial com barragens em 100 anos. Portal EBC. Disponível em: http://agenciabrasil.ebc.com.br/geral/noticia/2016-01/desastreemmariana-e-o-maior-acidente-mundial-com-barragens-em-100-anos. Acesso em: 21 abr. 2018.

PEloggiA, A. U. G.; OliveIRA, A. M. S. Tecnógeno: um novo campo de estudos das geociências. 2005. Disponível em http://www.abequa.org.br/mostra_sessao. Acesso em: 18 nov. 2019.

PEREZ FILHO, A.; QUARESMA, C. C. Ação Antrópica Sobre As Escalas Temporais dos Fenônemos Geomorfológicos. Revista Brasileira de Geomorfologia, v. 12, n. 3, p. 83-90, 2011.

POEMAS. Antes fosse mais leve a carga: avaliação dos aspectos econômicos, políticos e sociais do desastre da Samarco/Vale/BHP em Mariana (MG). Mimeo 2015. Disponível em: HTTP://www.ufjf.br/poemas/files/2014/PoEmas-2015.pdf. Acesso em: 25 de ago. 2017.

SOUZA, L. A.; SOBREIRA, F. G.; PRADO FILHO, J. F. Cartografia e Diagnóstico Geoambiental aplicados ao ordenamento territorial do Município de Mariana - MG. UFOP, 30/12/2005. 